\title{
Intractable Sneezing Unfolding a Hideous Truth
}

\author{
Jia Ji Ng ${ }^{1}$, Salina Husain ${ }^{1}$, Hui Yan Ong ${ }^{2}$, Farah Dayana Zahedi ${ }^{1}$, Aneeza Khairiyah Wan Hamizan ${ }^{1}$ \\ 1. Department of Otorhinolaryngology - Head and Neck Surgery, Universiti Kebangsaan Malaysia Medical Centre, Kuala \\ Lumpur, MYS 2. Department of Otolaryngology - Head and Neck Surgery, University of Malaysia Medical Centre, Kuala \\ Lumpur, MYS
}

Corresponding author: Salina Husain, drsalina_h@yahoo.com

\begin{abstract}
Intractable sneezing is a diagnosis of exclusion and is mostly psychogenic. We reported a case of an 11year-old girl who presented with uncontrollable bouts of sneezing for three weeks, which did not respond to conventional treatment. She was eventually diagnosed to have psychogenic intractable sneezing, which was triggered by an unfortunate family circumstance. She improved with psychotherapy and was discharged well. Literature review on intractable sneezing showed that patients were predominately female teenagers and mostly recovered after psychotherapy. Multidisciplinary team effort especially with a child psychiatrist is important for the treatment and follow-up of these patients. Imaging should also be routinely performed as some had underlying organic causes that presented as intractable sneezing.
\end{abstract}

Categories: Otolaryngology, Psychiatry, Psychology

Keywords: article review, conversion syndrome, sneezing, psychogenic, intractable sneezing

\section{Introduction}

Sneezing is a protective reflex to nasal irritation. It is mediated by a complicated two-step pathway consisting of nasal and respiratory phases and can be stimulated by various stimuli [1,2]. When the normal reflex pathway is disrupted or perturbed, sneezing can increase in severity and frequency to the extent of causing severe distress to the affected patients, leading to a diagnosis of intractable sneezing [3]. There are various etiologies of intractable sneezing, but the most commonly reported is the psychogenic cause [3]. We present a case of psychogenic intractable sneezing in an adolescent female who experienced debilitating sneezing following an unfortunate incident. Studies in the literature were reviewed and summarized from 1995 onward, with the following keywords: "intractable sneezing", "psychogenic sneezing", and "paroxysmal sneezing”.

\section{Case Presentation}

A healthy 11-year-old girl presented with uncontrollable bouts of sneezing for three weeks. This started after coming home from swimming and since then, she would have sudden episodes of fierce sneezing, as much as 10 to 15 times per minute, lasting for a few hours. There was no precipitating or relieving factor. There were no associated nasal symptoms, such as nasal itchiness, nasal blockage, nasal discharge, excessive lacrimation, or even cough. She had multiple visits to the general practitioner and was given intranasal steroidal sprays and even courses of antibiotics. The sneezing spell subsided for a few days and recurred in a more severe manner. It is interesting to note that the sneezing did not occur during her meal and sleeping time. It did, however, affect her daily activities, and her studies in school were greatly disturbed.

๑ Copyright 2021 $\mathrm{Ng}$ et al. This is an open access article distributed under the terms of the Creative Commons Attribution License CC-BY 4.0., which permits unrestricted use, distribution, and reproduction in any medium, provided the original author and source are credited.
She was brought for an ENT consultation at a private hospital and underwent functional endoscopic sinus surgery, as minimal mucosal thickening on the left ethmoidal sinus was noted. However, the sneezing bouts continued at day 1 postoperatively and became more severe following that. She was then referred to our center for a second opinion.

During the consultation, the child was having one of her sneezing spells. She was sneezing with her eyes opened and it was not precipitated by deep drawing of breath. She denied any history of physical or emotional abuse. Nasal endoscopy revealed healthy nasal mucosa, normal inferior turbinate, and enlarged adenoids.

The skin prick test for allergies was negative, and a magnetic resonance imaging (MRI) scan of the brain revealed normal findings. She was eventually referred to pediatric and psychiatric teams for further assessment. Shockingly, after a few sessions with the child psychiatrist, she revealed that she was touched inappropriately by a close family member on a few occasions. She was mentally disturbed by the incidences. The diagnosis of psychogenic intractable sneezing was made. Her parents were informed of her condition, and she was commenced on psychotherapies. Her symptoms improved eventually, and her sneezing attacks ceased after the therapy sessions. Verbal consent was obtained from the patient and her parents. Her anonymity was preserved throughout the case report. 


\section{Discussion}

Sneezing was first defined by Brubaker in 1919 as spasmodic expiration preceded by one or more spasmodic inspirations [4]. A simple sneeze is initiated by a complicated two-step pathway. It starts with a sensory or nasal phase followed by an efferent or respiratory phase. The sensory phase is activated by chemical or mechanical stimulants onto the nasal mucosa. These sensory impulses travel via the ethmoidal and olfactory nerve to the sneezing center, which is located in the dorsolateral medulla $[1,2]$. This explains why patients with medulla stroke, lateral medullary syndrome, and sometimes neoplasm of this region may lose the ability to sneeze [5-7].

Mucosal edema and nasal secretions resulting from the nasal phase will then activate the second phase of sneezing, which is the respiratory phase. The respiratory phase requires synchronization of the respiratory, pharyngeal, and laryngeal musculature [8]. This efferent phase begins with eyes closure and an initial deep inspiration follows by forced expiration against a closed glottis causing increased intrathoracic pressure. With the opening of the glottis, the air is expelled explosively through the mouth and nose.

Intractable sneezing could be due to numerous etiologies, including allergic reactions, infections, anatomical abnormalities such as septal deviation, foreign body, and turbinate hypertrophy, seizure disorders, and vasomotor nasal congestion $[9,10]$. Interestingly, uncontrollable sneezing has also been reported as the sole presenting complaint in patients with medulla stroke $[5,11]$. However, the majority of reported cases of intractable sneezing are psychogenic. Thus, psychogenic intractable sneezing is defined as "sudden violent sneezing of unusual frequency and duration that is generally psychogenic in origin and is resistant to usual treatment" [3]. It was first reported in 1949, and over the years, most of the patients reported were adolescent girls aged 10 to 14 years [12-14]. It is a diagnosis of exclusion and a symptom of conversion disorder.

Articles search from PubMed and Google Scholar from the year 1995 and beyond using keywords "intractable sneezing", "psychogenic sneezing”, and "paroxysmal sneezing" revealed 17 case reports that involved a total of 19 patients (Table 1). Among patients diagnosed with psychogenic sneezing, the age ranged from 8 to 16 years, and they were predominately females. Most of them seek treatment within two weeks of presentation, and their sneezing attacks did not occur during sleep. All reported patients received psychotherapy with or without anxiolytic medications. Two patients were even treated successfully with placebo. However, imaging studies were not routinely performed for all patients. 


\begin{tabular}{|c|c|c|c|c|c|c|c|c|c|}
\hline & Author & Year & Age & Gender & $\begin{array}{l}\text { Symptom } \\
\text { Durations }\end{array}$ & $\begin{array}{l}\text { Occur at } \\
\text { Sleep }\end{array}$ & Imaging & Treatment & Etiology \\
\hline 1 & Mathew et al. [15] & 2017 & 10 & Male & 5 days & No & None & $\begin{array}{l}\text { Psychotherapy/ } \\
\text { alprazolam }\end{array}$ & Psychogenic \\
\hline 2 & $\begin{array}{l}\text { López-Chiriboga et } \\
\text { al. [16] }\end{array}$ & 2016 & 55 & Female & - & - & Yes & Plasmapheresis & $\begin{array}{l}\text { Neuromyelitis optica } \\
\text { spectrum disorder }\end{array}$ \\
\hline 3 & Mangot et al. [17] & 2015 & Teen & Female & 15 days & No & None & $\begin{array}{l}\text { Psychotherapy/ } \\
\text { sertraline }\end{array}$ & Psychogenic \\
\hline 4 & Mathis et al. [18] & 2014 & 50 & Male & 3 weeks & No & Yes & Surgery & $\begin{array}{l}\text { Papillary cardıac } \\
\text { fibroelastoma }\end{array}$ \\
\hline 5 & Then et al. [11] & 2013 & 95 & Male & 1 day & - & Yes & - & Ischemic stroke \\
\hline 6 & Chowdary [19] & 2013 & 11 & Female & 2 months & - & Yes & Psychotherapy & Psychogenic \\
\hline 7 & $\begin{array}{l}\text { González-Diaz et al. } \\
\text { [20] }\end{array}$ & 2012 & 14 & Female & 4 days & No & None & Psychotherapy & Psychogenic \\
\hline 8 & Sulemanji et al. [21] & 2011 & 11 & Female & 14 days & No & Yes & Psychotherapy & Conversion disorder \\
\hline 9 & Guner et al. [22] & 2010 & 12 & Female & 1 day & No & Yes & Haloperidol & Psychogenic \\
\hline 10 & Varshney et al. [23] & 2010 & 32 & Female & 3 days & No & Yes & $\begin{array}{l}\text { Psychotherapy/ } \\
\text { alprazolam }\end{array}$ & Conversion disorder \\
\hline 11 & Parke [24] & 2009 & 7 & Male & $\begin{array}{l}2 \text { years } \\
\text { (morning) }\end{array}$ & No & Yes & Surgery resection & Posterior fossa tumor \\
\hline 12 & De Sousa [25] & 2008 & 11 & Female & 7 days & No & Yes & Psychotherapy & Psychogenic \\
\hline 13 & Bhatia et al. [26] & 2004 & 16 & Female & 2 days & No & Yes & $\begin{array}{l}\text { Psychotherapy/ } \\
\text { alprazolam }\end{array}$ & Psychogenic \\
\hline 14 & Bhatia et al. [26] & 2004 & 16 & Female & 5 days & No & Yes & Psychotherapy & Psychogenic \\
\hline 15 & Lin et al. [27] & 2003 & 8 & Female & 8 days & No & None & Placebo & Psychogenic \\
\hline 16 & Lin et al. [27] & 2003 & 10 & Female & 3 days & No & None & Placebo & Psychogenic \\
\hline 17 & Browning [9] & 2002 & 12 & emale & 7 days & No & None & Psychotherapy & Psychogenic \\
\hline 18 & $\begin{array}{l}\text { García Callejo et al. } \\
\text { [28] }\end{array}$ & 2000 & 13 & Male & 18 days & No & Yes & Psychotherapy & Psychogenic \\
\hline 19 & Goldfarb et al. [29] & 1995 & 25 & Female & 3 months & - & Yes & Ethmoidectomy & Ethmoid sinusitis/ia \\
\hline
\end{tabular}

TABLE 1: Case Reports on Intractable Sneezing

Detailed history-taking is essential in eliciting possible underlying stressors and the psychiatric features of the disorder. Pre-existing psychiatric diagnosis, psychosocial circumstances, history of previous conversion symptoms, or interpersonal relationship issues should be explored and addressed accordingly. Building good rapport with patients and their family is important, and the approach should be non-judgmental. In this case, the history of sexually inappropriate touching was only disclosed after multiple up-close encounters with a trustable child psychiatrist.

Physical examination for patients with psychogenic intractable sneezing is mostly unremarkable. Careful observation may be able to distinguish between physiology and psychogenic sneezing as they demonstrate numerous atypical characteristics. Patients tend to sneeze with their eyes open, associated with minimal inspiratory phase and minimal aerosolization of secretions, as well as minimal facial expression. The rate and rhythm of sneezing are abnormal, and they are resistant to conventional treatments [14].

Furthermore, investigations, such as blood tests, allergies tests, or even imaging, may also be normal in most cases. However, routine imaging is still advocated to rule out any underlying pathology. For instance, Parke reported a case of a seven-year-old boy who had intractable sneezing and was eventually diagnosed with a 
posterior fossa tumor [24]. Incidental findings on the imaging may also be the cause of the intractable sneezing, as evidenced in the case reported by Goldfarb et al., whereby a patient with intractable sneezing was found to have ethmoidal sinusitis on computed tomography (CT) imaging, which improved after endoscopic ethmoidectomy [29]. Imaging is also important especially for elderly patients with intractable sneezing as most of them would have an underlying pathology.

Several treatment modalities have been suggested for intractable sneezing in previous literature with varying success rates [14,22,27]. Medications such as intranasal corticosteroids, antihistamines, decongestants, subcutaneous epinephrine, and even anxiolytic medications have been used [22,27]. Placebo treatment with isotonic sodium chloride had also been used with satisfying results [27]. For psychogenic intractable sneezing, psychotherapy is the mainstay of treatment. Most of them recovered after psychotherapy. Family members' participation and involvement may be helpful, especially in pediatric or adolescent patients. If this fails, hypnosis or even amytal interview can be used as a last resort to get additional information about the psychogenic stressor contributing to the symptom expression [14]. Patients with psychogenic intractable sneezing should be given long-term medical follow-ups as they may develop an organic or psychiatric illness later in their lives.

\section{Conclusions}

Intractable sneezing is a debilitating condition and is commonly due to patients' underlying psychogenic illness. Detailed history taking and physical examination, as well as imaging, should be performed to rule out any underlying organic causes as summarized in the literature review. Clinical suspicion, sensible and empathic approach, and good family support would enable prompt diagnosis and treatment, which, in turn, would reduce future physical and psychosocial complications.

\section{Additional Information}

\section{Disclosures}

Human subjects: Consent was obtained or waived by all participants in this study. Conflicts of interest: In compliance with the ICMJE uniform disclosure form, all authors declare the following: Payment/services info: All authors have declared that no financial support was received from any organization for the submitted work. Financial relationships: All authors have declared that they have no financial relationships at present or within the previous three years with any organizations that might have an interest in the submitted work. Other relationships: All authors have declared that there are no other relationships or activities that could appear to have influenced the submitted work.

\section{References}

1. Wallois F, Macron JM, Jounieaux V, Duron B: Trigeminal nasal receptors related to respiration and to various stimuli in cats. Respir. Physiol. 1991, 111:125. 10.1016/0034-5687(91)90010-G

2. Fink JN: Localization of the "sneeze center". Neurology. 2001, 56:138. 10.1212/wnl.56.1.138

3. Kaplan MJ, Lanoff G: Intractable paroxysmal sneezing. A clinical entity defined with case reports . Ann Allergy. 1970, 28:24-7.

4. Brubaker AP: The physiology of sneezing. JAMA. 1919, 73:585-7. 10.1001/jama.1919.02610340017004

5. Seijo-Martínez M, Varela-Freijanes A, Grandes J, Vázquez F: Sneeze related area in the medulla: localisation of the human sneezing centre?. J Neurol Neurosurg Psychiatry. 2006, 77:559-61. 10.1136/jnnp.2005.068601

6. Hersch M: Loss of ability to sneeze in lateral medullary syndrome . Neurology. 2000, 54:520-1. 10.1212/wnl.54.2.520

7. Martin RA, Handel SF, Aldama AE: Inability to sneeze as a manifestation of medullary neoplasm. Neurology. 1991, 41:1675-6. 10.1212/wnl.41.10.1675

8. Nishino T: Physiological and pathophysiological implications of upper airway reflexes in humans . Jpn I Physiol. 2000, 50:3-14. 10.2170/jiphysiol.50.3

9. Hotaling J, Park AH, Chow JM: A case of intractable sneezing: ‘a pleasure sent from God?' . Int J Pediatr Otorhinolaryngol. 1994, 30:63-70. 10.1016/0165-5876(94)90052-3

10. Gopalan P, Browning ST: Intractable paroxysmal sneezing. J Laryngol Otol. 2002, 116:958-9. 10.1258/00222150260369543

11. Then R, Dominguez F, Robbins MS: Paroxysmal sneezing heralding embolic cerebral infarction. J Am Geriatr Soc. 2013, 61:168-9. 10.1111/jgs.12052

12. Shilkret HH: Psychogenic sneezing and yawning. Psychosom Med. 1949, 11:127. 10.1097/00006842194903000-00007

13. Co S: Intractable sneezing: case report and literature review . Arch Neurol. 1979, 36:111-2. 10.1001/archneur.1979.00500380081012

14. Fochtmann LJ: Intractable sneezing as a conversion symptom . Psychosomatics. 1995, 36:103-12. 10.1016/S0033-3182(95)71679-6

15. Mathew B, Neelannavar R, Marulasiddappa PM: Psychogenic sneezing. Indian Pediatr. 2017, 54:878. 10.1007/s13312-017-1153-8

16. López-Chiriboga AS, Huang JF, Flanagan EP, Cheshire WP Jr: Paroxysmal sneezing in NMOSD: further evidence of the localization of the human sneeze center. Neurol Neuroimmunol Neuroinflamm. 2017, 4:e303. 10.1212/NXI.0000000000000303

17. Mangot AG, Trivedi S, Pandey A, Saimbi D, Dubey V: Psychogenic sneezing. J Neurosci Rural Pract. 2015, 6:282-3. 10.4103/0976-3147.153242 


\section{Cureus}

18. Mathis S, Lamy M, Ciron J, Iljicsov A, Arjmand R, Agius P, Neau JP: Paroxysmal sneezing at the onset of syncopes and transient ischemic attack revealing a papillary cardiac fibroelastoma. Case Rep Neurol Med. 2014, 2014:734849. 10.1155/2014/734849

19. Chowdary VS: Environmental and occupational respiratory diseases - 1051. Intractable sneezing - case report. World Allergy Organ J. 2013, 6:P50. 10.1186/1939-4551-6-S1-P50

20. González-Díaz S, Arias-Cruz A, Mejia K, Gallego C, Garcia-Calderin D, Calva M, Dominguez L: Psychogenic intractable sneezing. Case report. World Allergy Organ J. 2012, 5:S118. 10.1097/01.WOX.0000412076.68032.f3

21. Sulemanji MN, Kanbur NO, Derman O, Pehlivantürk B, Hoşal SA, Sekerel BE: Intractable sneezing: is it always psychogenic?. Turk J Pediatr. 2011, 53:225-8.

22. Guner SN, Gokcen C, Gokturk B, Topal O: Haloperidol: a possible medication for the treatment of exacerbation of intractable psychogenic sneezing. Int J Pediatr Otorhinolaryngol. 2010, 74:1196-8. 10.1016/j.ijporl.2010.07.012

23. Varshney S, Bist S, Singh R, Gupta N, Bhagat S: Intractable sneezing: case report and literature review . Clin Rhinol An Int J. 2010, 3:119-20.

24. Parke SC: Nothing to be sneezed at. J Pediatr Neurol. 2010, 8:397-8. 10.3233/JPN-2010-0416

25. De Sousa A: Childhood psychogenic sneezing. J. Pakistan. 2008, 5:41.

26. Bhatia MS, Khandpal M, Srivastava S, Khandpal M: Intractable psychogenic sneezing: two case reports. Indian Pediatr. 2004, 41:503-5.

27. Lin TJ, Maccia CA, Turnier CG: Psychogenic intractable sneezing: case reports and a review of treatment options. Ann. Allergy, Asthma Immunol. 2003, 91:575-8. 10.1016/S1081-1206(10)61537-2

28. García Callejo FJ, Ferrer Baixauli F, Martínez Beneyto MP, Orts Alborch MH: [A prolonged case of intractable sneezing. Pathophysiological hypothesis]. Acta Otorrinolaringol Esp. 2000, 51:188-92.

29. Goldfarb CA, Goldfarb M, Gerwin JM: Intractable sneezing : a case report. Otolaryngol. - Head Neck Surg. 1995, 113:313-5. 10.1016/S0194-5998(95)70127-3 